\title{
Control of Enzyme-Distribution in Enzyme-Membrane by Electric Field*
}

\author{
Shigeru KunugI, Hideyuki Yamada, Takaya NakaJma \\ and Yoshiharu NAKAMURA**
}

Department of Applied Chemistry, Fukui University, Fukui 910, Japan

(Received July 11, 1986)

By dint of electric field given during the polymerization process, alkaline phosphatase from porcine intestine was immobilized asymmetrically in photocrosslinkable resin prepolymer membrane through entrapment. Catalytic activities of two sides of the membrane and the transportcatalysis behavior were measured.

It was found that the conversion of the substrate, present in one chamber, to the product and the transport of the latter to the other side of the membrane were more efficiently carried out when the enzyme distribution in the matrix was inclined to the side of the membrane facing to the substrate-free chamber.

The same procedure was successfully applied to coimmobilize alcohol dehydrogenase from equine liver and formaldehyde dehydrogenase from yeast in one membrane with different (complementary) distributions of the enzymes with respect to the membrane thickness.

Key words: Immobilized enzyme, Electric field, Asymmetric membrane,

Transport-catalysis behavior

Asymmetric structure of biological membranes, such as lipid composition or protein distribution/ orientation, is one major basis of their high functionality as seen in selective permeation and anisotropic transport ${ }^{11}$. In order to model some of these points, we have prepared asymmetric charged membranes from acrylamide-methacrylic acid system by using an electric field ${ }^{21}$, and also applied the: same procedure to prepare an enzymeimmobilized membrane with an asymmetric distribution of the enzyme ${ }^{31}$. This method is based on the ionic nature of co-monomer or enzyme protein to be responsive to the given electric field. Namely, during the preparation of the membrane an elecrtic field was applied perpendicular to the membrane plane to influence the distribution of ionic substance in the resultant polymer membrane and fix them by copolymerization (charged membrane) or entrapment (enzyme membrane).

Though there have been a number of reports on membrane-type immobilized enzymes (enzyme membranes $)^{4}$, few experimental studies have concerned with the asymmetric nature of enzyme membranes. As a material for enzyme immobilization by an entrapment procedure, socalled photocrosslinkable resin prepolymers, developed by Fukui's group, are highly useful and have been applied for various biocatalysts in either form of membrane or cube ${ }^{5)}$. In the present study we applied our method to prepare asymmetric enzyme membranes by use of this type of material to improve the properties of the obtained enzyme membrane as well as to investigate a transport-catalysis coupling of the asymmetric membrane. Furthermore a possibility was checked to immobilize two enzymes having different ionic characters in one membrane with

** 功力 滋, 山田英幸, 中島貴也, 中村良治: 福井大学工学部応用反応化学科 $\mathbf{\top} 910$ 福井市文京 3-9-1 
different distributions by our electric field method.

\section{Experimentals}

Alkaline phosphatase from calf intestine (ALP, E.C. 3. 1.3.1. $)^{7)}$ was obtained from Sigma Chemical Co. (St. Louis, Mo. USA; Lot. 21F-0270). Disodium $p$-nitrophenylphosphate(pNPP) (Nakarai Chemicals, Kyoto) was used as the substrate. Horse liver alcohol dehydrogenase (HLADH, E. C. 1.1.1.1.) and formaldehyde dehydrogenase from yeast (YFDH, E.C. 1. 2. 1. 1.) were purchased from Hoechst Japan (Tokyo; Lot 406208) and Toyobo Co. (Osaka) (Lot. 3173), respectively. $\beta$-NAD ${ }^{+}$ and $\beta$-NADH were from Oriental Yeast Co. (Tokyo). Other chemicals are of commercial reagent grade and used without further purifications.

Photo-crosslinkable resin prepolymers derived from poly (ethylene glycol) (ENT) and from poly(propylene glycol) (ENTP) with $\mathrm{Mr}=4000$ of the main chain were kindly donated by Prof. A. Tanaka of Kyoto University. Immobilization was performed as in the literature ${ }^{6)}$. A solution containing enzyme(s) and a prepolymer was placed in a cell and sandwiched by PET films as illustrated in Fig. 1. A high electric potential (ca.10 $\mathrm{kV}$ ) was given between the platinum plate below the solution and the point-type counter electrode above the solution. After an incubation for 30 to $60 \mathrm{~min}$ in the dark, near UV light was given by a UV-lamp (National, FUL 14BA-37-K) for 5 to $7 \mathrm{~min}$ to complete solidification of the solution. The membrane thickness was controlled by a silicone-rubber frame placed between two PET sheets (usually $250 \mu \mathrm{m}$ ). The two sides of ithe obtained membrane were discriminated below by denoting bottom (B) or top (T) side, corresponding to the side during the polymerization process.

As a control, a membrane without an application of electric field was prepared by a similar procedure except for an absence of electric field. Membranes having two distinct layers were also

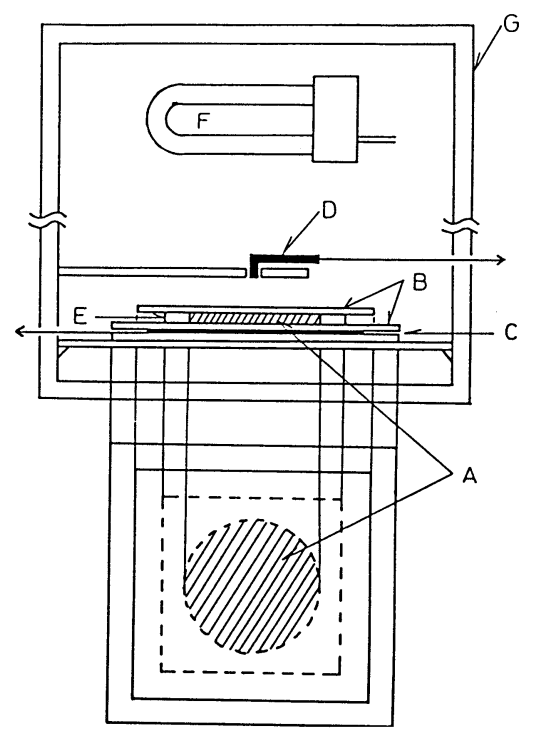

Fig.1 A schematic illustration of the membrane preparation cell.

A, Prepolymer-enzyme mixture; B, PET sheet: C, Platinum plate: D, Point-type counter electrode; E, Silicone rubber frame: F, Near UVlamp;. G, Incubate box.

prepared by two successive polymerizations, first without containing enzyme (in the case of ALP) or with one of the two enzymes and second with the (other) enzyme. The total thickness was designed to be similar to the single-layered membrane. In all cases the obtained membrane was washed in cold water for overnight and stored in cold.

The catalytic activity of ALP was assayed in $0.2 \mathrm{M}$ Tris buffer containing $50 \mathrm{mM} \mathrm{MgCl}_{2}$ and appropriate amount of pNPP by observing the absorbance increase (at $410 \mathrm{~nm}$ ) due to the product ( $p$-nitrophenol; pNP) of an aliquot from the solution by a UV-visible spectrophotomer (Jasco, Uvidec-610). Those of dehydrogenases were followed by the absorbance change of the coenzyme at around $340 \mathrm{~nm}$ by using benzyl alcohol (HLADH) or acetic acid (YFDH) as the substrate in appropriate buffers.

Thus prepared enzyme-membrane was placed between two solution chambers ( $\mathrm{L}$ and $\mathrm{R}, 30 \mathrm{ml}$ 
for each) having $30 \mathrm{~mm}^{\phi}$ window in the membrane-side wall of each chamber and the substrate solutions of the identical concentration were set in two chambers. Solutions were sufficiently stirred by magnetic stirrers and an aliquot was taken at indicated interval to measure the optical absorbance. The transportcatalysis coupling was measured with a similar set of chambers except for the substrate supplied only in one side (L-side) of the chambers.

\section{Result and Discussions}

Figure 2 shows typical time-dependent absorbance changes in the two chambers for an ENT-ALP membrane prepared at $\mathrm{pH} 8$ under +10 $\mathrm{kV}$. The apparent reaction rate is calculated from the slope. The relative catalytic activity of the B-side of the membrane over the T-side $\left(V_{B} /\right.$ $V_{T}$ ) was calculated as 2.3 for this particular case. Similar asymmetry was observed with membranes prepared under $8-10 \mathrm{kV}$ but activity asymmetry was lower in membranes prepared under further lower electric field, though detailed data are not shown here. A membrane prepared in the absence of an electric field showed a $V_{B}$ / $V_{T}$ value of 1.1. This result is explained when we consider that ALP has a pI value of around 5 and hence was held at the experimental $\mathrm{pH}$ (8) to be negatively charged. Thus ALP was attracted by the positively polarized surface during the immobilization process and resulted in an asymmetric enzyme-membrane. Since the substrate and the product can diffuse toward both sides of the membranes during the kinetic assay, the apparent asymmetry of the activity as obtained in Fig. 2 implies much higher asymmetric distribution of the enzyme in the membrane ${ }^{8)}$. Even for a composite membrane in which one half of. the thickness contains no enzyme the $V_{B} / V_{T}$ value was measured as 4.8. When ENT was partly displaced by ENTP to change the hydrophobicity of the membrane (up to $40 \%$ by weight), similar asymmetry in the activity was observed, though

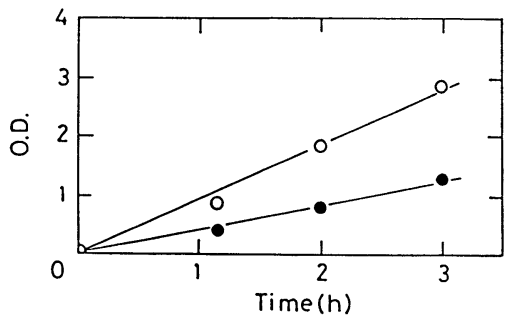

Fig. 2 Typical time profiles of the absorbance at $410 \mathrm{~nm}$ of the solutions in the two chambers facing to the ALPimmobilized membrane prepared under $+10 \mathrm{kV}$.

, change in the chamber facing to the bottom side of the membrane. $O$, change in the chamber facing to the top side of the membrane. At $25^{\circ} \mathrm{C}$ and $\mathrm{pH} 10.0$.

$[\mathrm{pNPP}]=15 \mu \mathrm{M}$ in both chambers.

detailed data are not shown here.

As for the effect of anisotropy or asymmetry on the transport-reaction behavior of enzyme membranes, Ciftci and Vieth ${ }^{9)}$ showed that the optimum distribution for maximizing emergent product flux was one where the enzyme concentration was shifted toward the downstream side ( $\mathrm{R}$-side) of the membrane when the enzyme concentration in the membrane varied linearly with the thickness of the enzyme $([E]=k x ; k$, constant and $x$, thickness) or stepwise and when such membranes were placed between two chambers one of which ( $\mathrm{R}$-side) was free from the substrate. They assumed that the substrate concentration was not too much excess over Michaelis constant, which is similar to the present case, and that the diffusion constants of the substrate and the product were equal, which is also approximately realized in the present case since the membrane matrix is fundamentally neutral and the measured permeation coefficients of pNPP and pNP differed only by a factor of two at $25^{\circ} \mathrm{C}$ and $\mathrm{pH} 10$.

We measured the ratio of the product out-flux from the membrane into the substrate-free (R) chamber to the consumption of the substrate in the opposite side (L) chamber $\left(=F_{\mathrm{pr}} / F_{\mathrm{sl}}\right)$ for 
Table 1 Enzyme activity ratio of the two sides of the enzyme membranes prepared under different conditions and their transport-catalysis properties at $25^{\circ} \mathrm{C}$

\begin{tabular}{cccc}
\hline \multicolumn{2}{c}{$\begin{array}{c}\text { Membrane } \\
\text { Code }\end{array}$} & $V_{B} / V_{T}$ & \multicolumn{2}{c}{ Anisotropy** } \\
$F_{\mathrm{pr}} / F_{\mathrm{s} 1}$ \\
\hline $\mathrm{I}$
\end{tabular}

*) Shaded parts schematically represent the location of the enzyme. This doesn't mean the actual profile of the enzyme distribution of III is linear with respect to the membrane thickness. It will be more or less nonlinear. Substrate-containing solution is to be placed in the left side of the profile. ${ }^{* *}$ Ratio of the $F_{\text {pr }} / F_{\text {sl }}$ values in two directions.

three membranes prepared by different ways (Table 1). We can see distinct profits in the product-conversion efficiency for the two-layered membrane (membrane II) and the membrane prepared under the electric field (membrane III). This is the first experimental result for the above mentioned theoretical prediction and is different from our previous result for an acrylamide-based asymmetric membrane ${ }^{3)}$, where no distinct difference was observed in $F_{\mathrm{pr}} / E_{\mathrm{s} 1}$. This would be related to the thickness of the previous membranes. Compared to the apparent asymmetry of the activity, the preferential $F_{\mathrm{pr}} / E_{\mathrm{s} 1}$ value of membrane III was closer to that of membrane II when both membranes were placed so as the enzyme-rich side to face to the substrate-free chamber (R).

The present technique can further be applied to prepare a membrane containing two or more enzymes whose distributions in the matrix are different from each other. To realize this, we must select enzymes having appropriately different isoelectric points. As the target we focused on the conjugated dehydrogenase system to regenerate nicotinamide coenzyme ${ }^{10)}$. Among a
Table 2 Catalytic Activities of the Two Sides of the HLADH-YFDH-Coimmobilized Membranes.

Membrane

Code Profile* $V_{B} / V_{T}$ for $\mathrm{ADH} \mid V_{B} / V_{T}$ for FDH

\begin{tabular}{|c|c|c|c|}
\hline & W & 1.33 & 1.02 \\
\hline II & 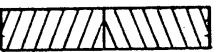 & 0.29 & 1.79 \\
\hline III & W & 0.56 & 1.53 \\
\hline
\end{tabular}

* /// represents one enzyme and $\backslash / \backslash$ the other. In membrane III the profile is only schematic and doesn't mean the actual distribution is linear with respect to the thickness, just as in the case of Table 1.

number of dehydrogenases available at laboratories, following combination was chosen; equine liver $\mathrm{ADH}(\mathrm{pI}=9-10)^{11)}+$ yeast $\mathrm{FDH}(\mathrm{pI}=5.2)^{12)}$, though a recent report ${ }^{13}$ indicated that glucose dehydrogenase was better than FDH for a conjugated reaction of co-enzyme regeneration system with ADH. These enzymes were preliminary checked to be actively immobilized with the present prepolymers. The result with ENT is shown in Table 2 where the activity ratio of two sides of the membrane for each enzyme was measured independently. Since immobilization was performed at $\mathrm{pH} 7$ (Hepes buffer) HLADH was positively charged and YFDH was negatively charged. The former was repelled by the positively polarized platinum side while the latter was attracted to it. Considerable asymmetry was observed for each enzyme activity in the membrane obtained by the electric field method and the value was none the worse than the composite membrane where two enzymes were separately immobilized in the manner explained in the experimental section. It is clear that the present procedure is successfully applied to the immobilization of two-enzyme system and such a membrane will be usefully applied for e.g., membrane reactors. 
This work was partly supported by the Grantin-Aid on Special Project Research for "Organic Thin Films for Information Conversion" from the Ministry of Education, Science and Culture.

The authors gratefully acknowledge Prof. A. Tanaka and Dr. K. Sonomoto, Department of Industrial Chemistry, Kyoto University, for the kind donation of the prepolymer materials and their helpful advices.

\section{References}

1) J.E.Rothman, J.Lenard: Science, 195, 743 (1977)

2) Y. Nakamura, Y. Saitoh, Y. Obata, S.Kunugi : J. Soc.Fib. Sci. Tech. Jpn. (Sen-i Gakkaishi) $41 \mathrm{~T}-173$ (1985)

3) S. Kunugi, H. Kodama, H. Yamada, Y. Nakamura: J.Soc.Fib.Sci. Tech. Jpn. (Sen-i Gakkaishi), 41 T-355 (1985)

4) S. Suzuki, M. Karube: Membrane (Maku),
膜 (MEMBRANE), Vol. 12 No.2 (1987)

105

6, 148 (1981) ; M. Karube: Membrane (Maku), 7, 332 (1982) ; S. Kunugi: Sen-i to Kogyo, 41, p-205 (1985)

5) S. Fukui, A. Tanaka, T. Iida, E. Hasegawa : FEBS Lett., 66, 179 (1976); A. Tanaka, S. Yasuhara, S. Fukui, T. Iida, E. Hasegawa : J. Ferment. Technol., 55, 71 (1977)

6) S. Fukui, A. Tanaka: Adv. Biochem. Engin. Biotech., 29, 1 (1985)

7) H. N. Fernly: "The Enzymes, Vol. IV", 3rd Ed., (P.D.Boyer ed.,) pp. 417, Academic Press, New York (1971)

8) M. Kubín, P. Spaček: Polymer, 14, 505 (1973)

9) T. Ciftçi, W. R. Vieth: J. Mol. Catal., 8, 455 (1980)

10) S. S. Wang, C. K. King : Adv. Biochem. Eng., 12, 119 (1979)

11) C.-I. Brändén, H. Jörnvall, H. Ek'und, B. Furugren: The Enzymes (3rd. Ed) 11, 103 (1975

12) M. Ando, T. Yoshimoto, K. Rikitake, S. Shibata, D. Tsuru: J. Biochem., 85, 1165 (1979)

13) C.-H. Wong, D. G. Drrueckhammer, H. M. Sweers: J. Amer. Chem. Soc., 107, 4028 (1985) 